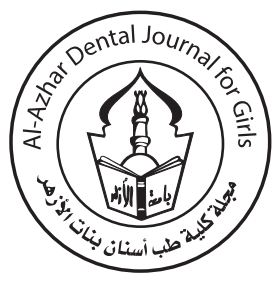

\title{
The Anticipated Effect of Glycogen Synthase Kinase 3 (GSK3) Antagonist on Pulp Tissue Repair in Rabbits
}

\author{
Fatema F. Elturki ${ }^{1 *}$, Mona H. Farid ${ }^{2}$, Heba A. Adawy ${ }^{3}$
}

\begin{tabular}{|l|}
\hline Codex : 11/21.10 \\
azhardentj@azhar.edu.eg \\
http://adjg.journals.ekb.eg \\
\hline DOI: 10.21608/adjg.2021.28291.1248 \\
\hline $\begin{array}{l}\text { Oral Medicine \& Surgical Sciences } \\
\text { (Oral Medicine, Oral \& Maxillofacial } \\
\text { Surgery, Oral Pathology, Oral Biology) }\end{array}$
\end{tabular}

\section{KEYWORDS}

Tideglusib,

Glycogen synthase kinase-3

antagonist,

Pulp tissue repair.

\begin{abstract}
Purpose: To investigate the effect of Glycogen Synthase Kinase-3 (GSK3) antagonist on pulp tissue repair in rabbits. Materials and Methods: 24 adult healthy male rabbits were used in this study divided into three main groups: Group I (control): 2 rabbits with normal teeth without pulp exposure. Group II (TG): The exposed pulps of right posterior teeth of 22 rabbits were capped with KolSpon in association with $34 \mathrm{nM}$ Tideglusib. Group III (MTA): The exposed pulps of left posterior teeth of 22 rabbits were capped with Mineral Trioxide Aggregate (MTA). The 2 rabbits with normal teeth and 6 rabbits with pulp capped posterior teeth were euthanized after one day. Their DNAs were extracted and tested for expression of Axin 2 and $\beta$-actin by qPCR. 8 rabbits were euthanized after 4 weeks, and another 8 was euthanized after 6 weeks. The teeth were collected and prepared for immunohistochemical study using anti- $\beta$-catenin antibody. Results: The qPCR results showed the higher expression of Axin2 in the Tideglusib group than control group (without treatment) by about 5 folds and about 1.5 fold in the MTA group. The immunohistochemical results revealed the increase intensity in the Tideglusib group than MTA at four weeks with no significance difference $(p>0.05)$. Whilst after 6 weeks the higher expression was in Tideglusib group with significance difference $(\mathrm{p}<0.05)$. Conclusion: The Tideglusib drug stimulates the expression of Axin2 transcription factor gene which is known to play a key role in regulation of odontoblast and osteoblast differentiation.
\end{abstract}

\section{INTRODUCTION}

The dentin-pulp complex is the inner part of the tooth underneath the surface enamel layer in the crown of the tooth and thin layer of cementum in its root. Dentin is the hard tissue portion of this complex and it is formed by odontoblasts [highly specialized mesenchymal

- Paper extracted from Doctor thesis titled "The Anticipated Effect of Glycogen Synthase kinase 3 (GSK3) Antagonist on Pulp Tissue Repair in Rabbits"

1. Assistant Lecturer of Oral and Dental Biology, Faculty of dentistry, Benghazi University, Benghazi, Libya

2. Professor of Oral and Dental Biology, Former Dean of the Faculty of Dental Medicine for Girls, Al-Azhar University, Cairo, Egypt

3. Professor and head of Oral and Dental Biology, Faculty of Dental Medicine, Al-Azhar University, Cairo, Egypt

* Corresponding author email: dent_fa@yahoo.com 
cells]. Odontoblasts are also responsible for the dentin repair along its life ${ }^{(1,2)}$.

When tooth subjected to infection [dental caries] or trauma, the pulp tissue can be exposed and become infected leading to the activation of the natural repair process. This process is depending on the severity of the injury. With milder injury, affected odontoblasts may survive and secrete a reactionary type of tertiary dentin to increase the barrier between the injury and the cells of the pulp. Sever injury can lead to local odontoblast death then the tertiary (reparative) dentin is formed by odontoblast-like cells which are differentiated from mesenchymal stem cells in the pulp tissue ${ }^{(3-5)}$.

Although large lesions, as deep caries cannot be compensated by natural repair process, current clinical tooth repair involving the usage of mineral aggregates which are used to restore the cavity in dentin that formed after removal of trauma or caries. This mineral aggregates remain in the prepared cavity and will not degrade, so normal mineral volume cannot be restored completely ${ }^{(6,7)}$.

The activation of Wnt/ $\beta$-catenin signalling is the immediate response to the tissue damage and shows to be crucial for provoking the cellular-based repair in various tissues ${ }^{(8,9)}$. This Wnt pathway is considered to be very important in regulation of different cellular functions such as differentiation, proliferation, and survival. Moreover it plays crucial role in many physiological processes such as stem cell differentiation, wound healing, angiogenesis and embryonic development ${ }^{(9,10)}$.

The essential component of the $\mathrm{Wnt} / \beta$-catenin signalling pathway is the $\beta$-catenin and considered to be the bottle-neck by which the main signals pass ${ }^{(11)}$. It regulates many of genes in different biological processes $^{(12,13)}$.For instance, studies showed that the activation of $\beta$-catenin in embryogenesis resulting in ectopic dental tissue formation, while inactivation of $\beta$-catenin in developing tooth leading to arresting of its development at the bud stage ${ }^{(14,15)}$.
Other studies demonstrated that tooth repair and development have many similar molecular mechanisms ${ }^{(16-18)}$. Moreover, several studies showed that $\beta$-catenin can regulate adipocyte, chondrocyte and osteoblast differentiation of stem cells ${ }^{(19-21)}$.

The key cytoplasmic component of Wnt/ $\beta$ catenin pathway is Glycogen synthase kinase 3 (GSK-3) enzyme that cause degradation of $\beta$-catenin and Axin 2 by phosphorylation, this occurs in the absence of binding of Wnt ligand. On the other hand, the presence of this ligand will result in inhibition of GSK-3 activity leading to inhibition of $\beta$-catenin phosphorylation and attenuate its degradation. Unphosphorylated $\beta$-catenin then enter into the nucleus, where it interacts with the transcription factors [TCF/LEF1], this interaction leading to the activation the expression of WNT target gene includes Axin2 (Fig.1) ${ }^{(22-24)}$.

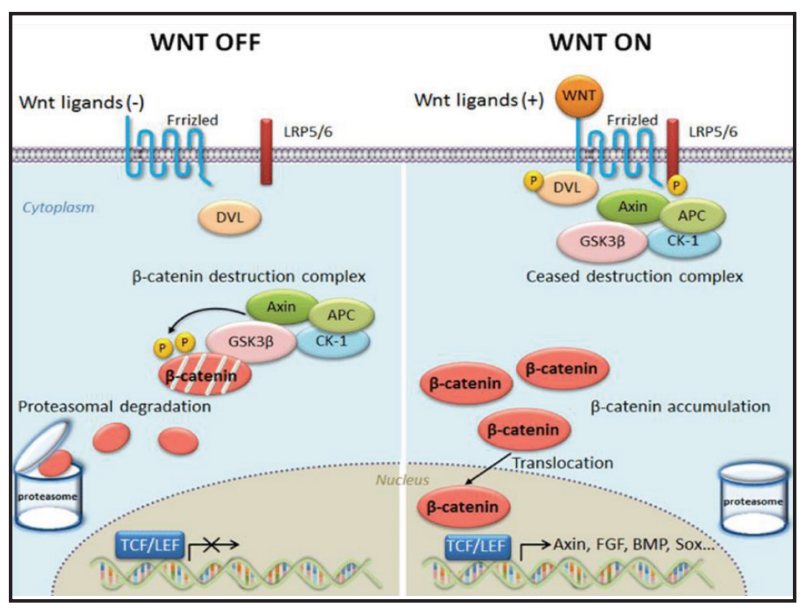

Figure (1) WNT/ $\beta$-catenin signalling. ${ }^{(24)}$

All the previous data confirmed that Axin2 expression after tooth damage is up-regulated by Wnt/ $\beta$-catenin signalling ${ }^{(25)}$. For this reason, inhibition of Wnt signalling by agonists causing stimulation of tertiary dentin formation leading to restoration of the lost dentin following tooth preparation with new formed dentin.

Recent studies of the involvement of the GSK-3 in many diseases pathways leading to emerge it in the 
pharmacological chemistry research field as a very interesting therapeutic target for the development of selective inhibitors as potential new drugs ${ }^{(24,26-29)}$. So glycogen synthase kinases 3 (GSK3) inhibitors drug have been developed. It up-regulate Wnt activity in various experimental studies very efficiently. Two studies of Tideglusib (4-Benzyl-2-(naphthalen-1yl)-[1,2,4] thiadiazolidine-3, 5-dione), is in clinical trials phase for Alzheimer's disease treatment ${ }^{(30,31)}$.

Given all the previous data, the authors hypothesized that reparative dentin may formed by participation of $\beta$-catenin in odontoblastic differentiation. This study was directed to test the ability of the GSK3 inhibitors drug to activate Wnt signalling pathway and stimulate Axin2 gene expression which subsequently stimulates tertiary dentin following experimentally induced pulp exposure.

\section{MATERIAL AND METHODS}

Twenty four adult healthy male rabbits of age ranging from 3-4 months, mean weight $(2.8 \pm 0.4)$ $\mathrm{kg}$ were used in this study. The rabbits were housed in Faculty of Pharmacy, Al-Azhar University and maintained in a $12 \mathrm{hr}$. dark-light cycle, with humidity of $50 \pm 5 \%$ and at a temperature of $22 \pm 3^{\circ} \mathrm{C}$ and good ventilation. The rabbits were fed fresh hay, water, and fresh vegetables. The study was conducted according to the guidelines of the institution's Animal Ethics Committee of Al-Azhar University.

\section{Steps of induced pulp exposure:}

The rabbits were anaesthetized by equal parts of katamin and xylazen subcutaneous injection ${ }^{(29)}$. Pulp exposure was induced by a round carbide bur (FG $1 / 4$ ) attached to a high speed hand piece until the dentin was reached, then the pulp was penetrated using a 30G needle. The pulp exposure was performed on right and left mandibular first molars.

\section{Pulp capping procedures:}

After pulp exposure, the animals were divided randomly into two experimental groups (I\& II) and control group:
Experimental Groups: Consists of 22 rabbits with 44 teeth, where in each rabbit, the pulp exposures were performed on right and left mandibular first molars.

- Group I: Pulp exposures were done on left mandibular first molars and capped with mineral trioxide aggregate (MTA) ( $n=22$ teeth).

- Group II: Pulp exposures were done on right mandibular first molars and capped with KolSpon in association with $34 \mathrm{nM}$ Tideglusib dissolved and diluted in DMSO (dimethyl sulfoxide) ( $\mathrm{n}=22$ teeth).

A layer of Glass Ionomer Cement was used as a seal over the capping material. Post-operatively, the rabbits were given analgesic injection.

Control Group: Consists of 2 rabbits with normal teeth without pulp exposure.

\section{Cytotoxicity test ${ }^{(32)}$}

Rabbit's pulp cells [cell Line] were obtained from American Type Culture Collection. It was supplied from cell culture department, VACSERA (Cairo, Egypt).These cells were cultured using Dulbecco's Modified Eagle Medium [DMEM] (Invitrogen/Life Technologies) supplemented with 10\% Fetal Bovine Serum (FBS) (Hyclone), $10 \mathrm{ug} / \mathrm{ml}$ of insulin [Sigma], and 1\% penicillin-streptomycin.

A volume of $100 \mu 1$ complete growth medium was poured in a 96-well plate with cell density of $1.2-1.8 \times 10,000$ cells/well; then $100 \mu \mathrm{l} /$ well of the tested agent were added to the plate and incubated for 24 hours before the MTT assay. For determination of the cell metabolic activity, MTT [3-(4, 5 Dimethylthiazol-2-yl]-2, 5- diphenyltetrazolium bromide, Sigma) was added to the conditioned media and controls after $24 \mathrm{hrs}$. Then the resulted formazan product was dissolved in $200 \mu 1$ of dimethyl sulfoxide per well (DMSO, Sigma). A background absorbance of multiwell plates at $690 \mathrm{~nm}$ was measured by a Spectrophotometer and subtract from the $450 \mathrm{~nm}$ measurement. 
At the day of scarification, each animal was decapitated after being euthanized by a lethal dose of diethyl ether anaesthesia. Their right \& left molar segments of the jaws were carefully dissected out. The lower first molars of animals from control and experimental groups that sacrificed after one day were extracted and kept in ice cold PBS then the DNA were extracted from its pulp to be used in the PCR. The specimens (from $4 \& 6$ weeks animals) were then prepared for immunohistochemical examination.

\section{Real-time Polymerase Chain Reaction (PCR)}

PCR technique was used to quantify the expression of genes (Axin2) and ( $\beta$-actin) ${ }^{(33)}$, as their expression was used to indicate the activation of Wnt pathway. mRNA isolation was carried out from the dental pulp that collected from rabbits without injury (control) and one day after injury using RNeasy extraction mini kit as recommended by the manufacturer instruction. Nanodrop was used to quantify the RNA and reverse transcribed into cDNA. Beta-actin was used as housekeeping gene (Forward-GGCTGTATTCCCCTCCATCG, Reverse- CCAGTTGGTAACAATGCCTGT) and Axin2 was the read-out for Wnt pathway activity (Forward-TGACTCTCCTTCCAGATCCCA, Reverse-TGCCCACACTAGGCTGACA). The reactions were incubated in a real-time thermal detection system (ROTOR-GENE 6000 HRM Real Time Rotary Analyzer) at $95^{\circ} \mathrm{C}$ for $10 \mathrm{~min}$ for one cycle and then $95^{\circ} \mathrm{C} /(15 \mathrm{sec}), 60^{\circ} \mathrm{C} /(60 \mathrm{sec})$ for about 40 cycles. Measurements for each donor were conducted in triplicate.

\section{Immunohistochemical study by using anti- $\beta$-catenin antibody to detect $\beta$-catenin in the pulp cells:}

The specimens were routinely fixed, dehydrated, cleared and paraffin wax embedded. Paraffin tissue sections were deparaffinized and rehydrated then antigen retrieval was conducted. The sections then were incubated with blocking buffer for one hour, then incubated with the primary antibody, rabbit polyclonal anti-Beta-catenin Antibody were purchased from (Bethyl laboratories inc. Montgomery, tx,USA). Detection of bound antibodies was done by the EconoTek HRP Anti-Polyvalent (DAB) kit were purchased from (ScyTek Laboratories, Inc., Utah, USA) as recommended by the manufacturer instructions. The slides were stained with diaminobenzidine (DAB) chromogen to detect the reaction product (Brown colored of epitope) ${ }^{(34)}$.

\section{Histomorphometric analysis:}

The histomorphometric measurements were performed using "Optics Image Analyzer Computer System" the analytical evaluation was done through the use of image analysis software (Image J, 1.41a, NIH, USA). Colour thresholding was performed automatically to convert the positive staining into measurement units (pixels) produced by the image analyzer program. The quantitative measurement analysis of immunohistochemical stain depends on the gray value from dark to light stain reaction which is from 0 up to 10: (0-1-intense, 2-3- strong, 3-4moderate, 4 up to 7 -weak). The data collected from the image analyzer were statistically analyzed.

\section{Statistical analysis:}

Statistical analysis was done using the (SPSS 20; SPSS, Chicago, IL, USA). Paired t-tests and independent t-tests were performed to compare the grade intensity of B -Catenin at 4 weeks and 6 weeks mean scores between Control Group (MTA group) and Experimental Group (Tideglusib group). $\mathrm{P}$-values $\leq 0.05$ was considered significant.

\section{RESULTS}

\section{A. MTT assay}

MTT assay showed that the highest concentration of Tideglusib that was not cytotoxic to the pulp cells after 24 hours in culture was 34 uM (Table 1, Fig 2). 
Table (1) Results of cytotoxicity test of Tideglusib drug on dental pulp cells (DPS):

\begin{tabular}{|c|c|c|c|c|}
\hline Serial & Sample code & $\begin{array}{c}\text { Molecular } \\
\text { weight }\end{array}$ & Cells & $\begin{array}{c}\text { Results } \\
\text { (IC50 Um) }\end{array}$ \\
\hline 1 & Tideglusib & 334.39 & DPC & $34 \pm 1.26$ \\
\hline
\end{tabular}

\section{Tideglusib/DPC $\quad y=-11.258 x+$}

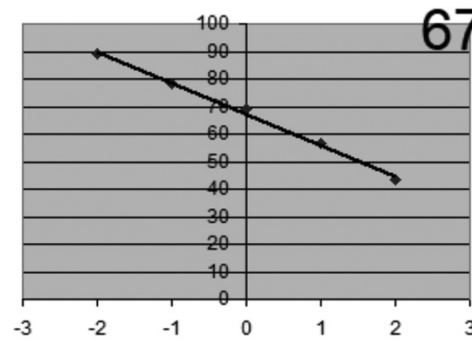

- Series1

—Linear (Series1)

Figure (2) Linear graph of cytotoxicity assay results

\section{B. PCR results:}

The qPCR results showed that the higher expression of Axin2 in the tooth treated with Tideglusib than control group (without treatment) by about 5 folds and about 1.5 fold in the tooth treated with MTA (Table 2, Fig 3).

\section{Immunohistochemical results:}

The immunohistochemical results of Tideglusib drug after 4 and 6 weeks showed expression of $\beta$-catenin in most odontoblasts as well as endothelial cell of blood vessels, where the 6 week group showed more intense reaction than that of the 4 weeks group. (Fig.4, 5). In MTA group, after 4 weeks the immunostaining showed diffuse moderate cytoplasmic reaction around the negative nuclei of odontoblasts (Fig.6). After 6 weeks, it was noted that there was a slight increase in $\beta$-catenin; moderate reaction was shown in odontoblasts with weak reaction in sub-odontoblast cells as well as in endothelial cells of blood capillaries (Fig.7).
Table 2: Results of PCR

\begin{tabular}{|c|c|c|}
\hline \multicolumn{2}{|c|}{ Sample data } & $\begin{array}{c}\text { Results } \\
\text { Fold Change }\end{array}$ \\
\hline Serial number & Sample code & Axin 2 FLD \\
\hline 1 & Ref (MTA) & $3.59 \pm 0.13$ \\
\hline 2 & Test (Tideglusib drug) & $5.13 \pm 0.18$ \\
\hline 3 & Control (Rabbit tooth cells) & 1 \\
\hline
\end{tabular}

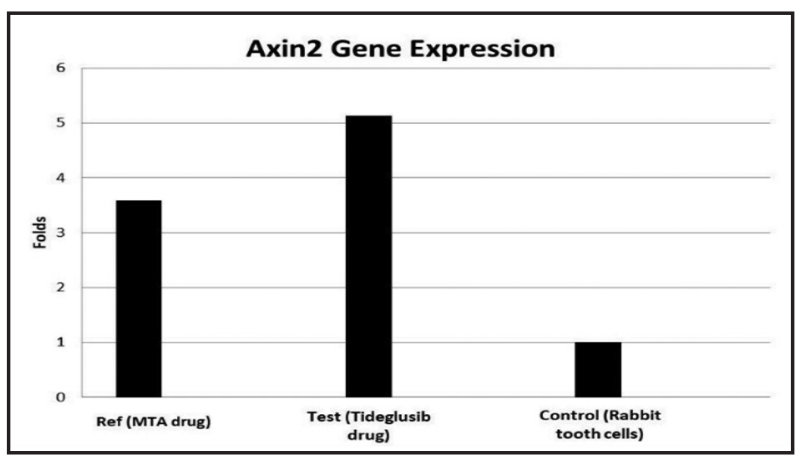

Figure (3) Bar graph of expression of Axin2 gene in dental pulps of control, ref (MTA) and test (Tideglusib) groups.

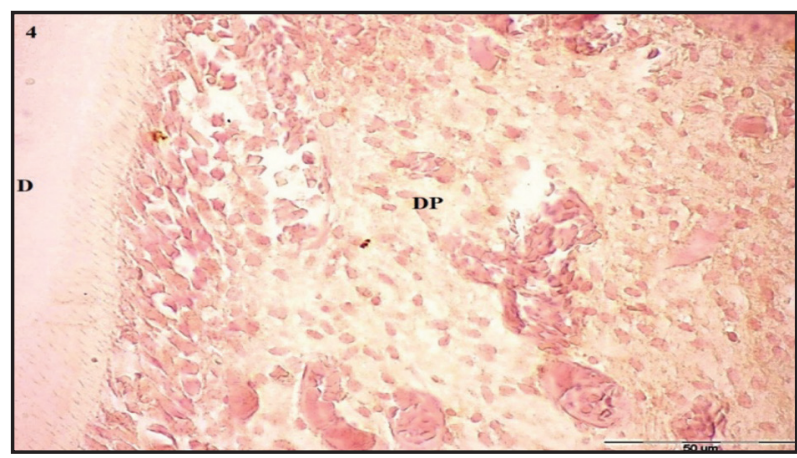

Figure (4) Photomicrograph of Tideglusib drug group after 4 weeks showing granular positive immunoreaction for $\beta$-catenin in dental pulp cells and blood capillaries; $\mathrm{D}$ : Dentin; DP: Dental Pulp (DAB, Bar $=50 \mu \mathrm{m})$.

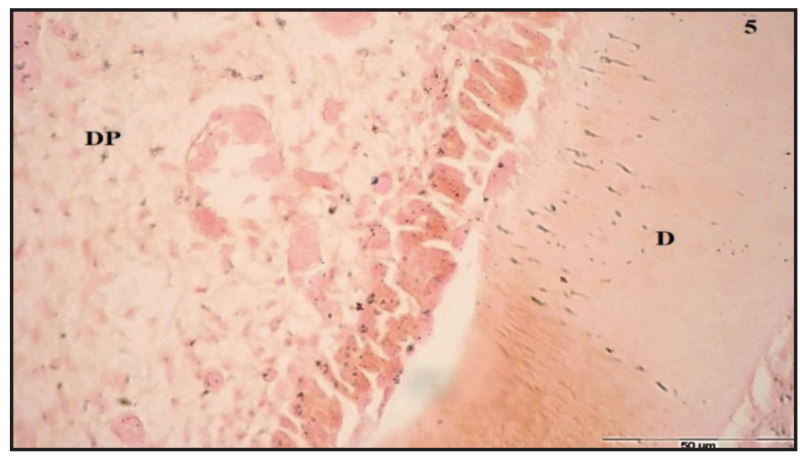

Figure (5) Photomicrograph of Tideglusib group after 6 weeks showing strong granular positive immunoreaction for $\beta$-catenin in odontoblasts, pulp cells, around blood capillaries and dentinal tubules $(\mathrm{DAB}, \mathrm{Bar}=50 \mu \mathrm{m})$. 


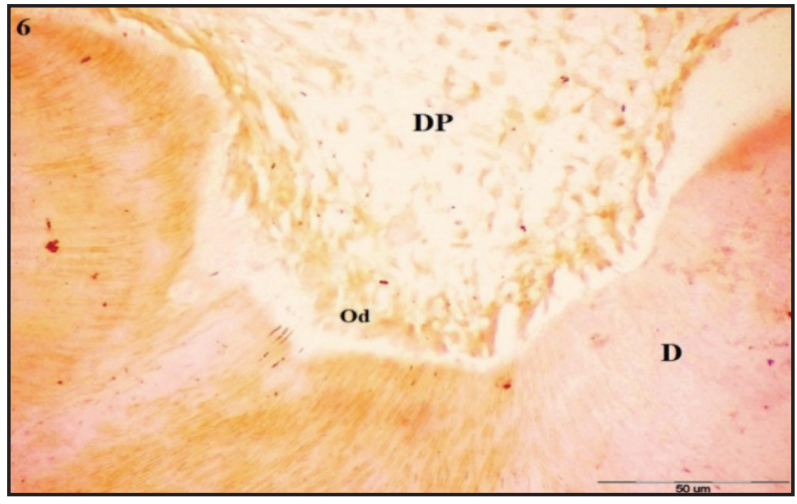

Figure (6) Photomicrograph of pulp tissue of MTA group after 4 weeks showing granular positive immunoreaction for $\beta$-catenin in odontoblasts, most pulp cells and endothelial cells (DAB, Bar $=50 \mu \mathrm{m})$.

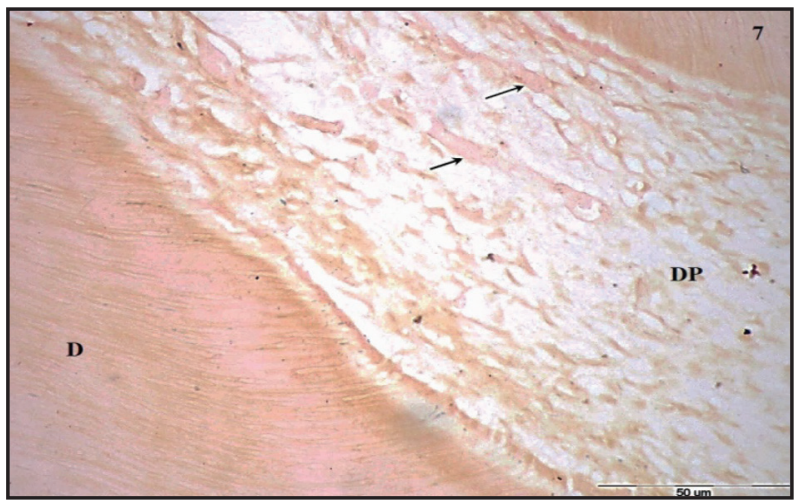

Figure (7) Photomicrograph of MTA group after 6 weeks showing moderate diffuse positive reaction of $\beta$-catenin in odontoblastic cells and weak reaction in subodontoblastic cells. Note weak reaction in endothelial cells of few blood vessels (arrows) (DAB, Bar $=50 \mu \mathrm{m})$.

\section{Statistical analysis:}

The analysis of collected data showed a significant decrease of the positive staining of $\beta$-catenin between the Tideglusib group and MTA group. The highest mean value of $\beta$-catenin was recorded in Tideglusib group in both 4 and 6 weeks, with only significant difference between the groups in 6 weeks (Fig 8, 9).

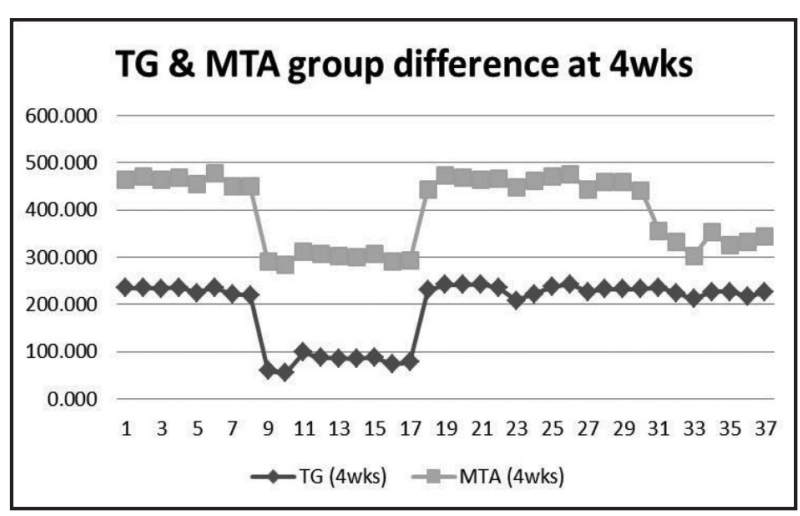

Figure (8) Linear graph chart illustrates the difference between both groups (TG \& MTA) at 4 weeks

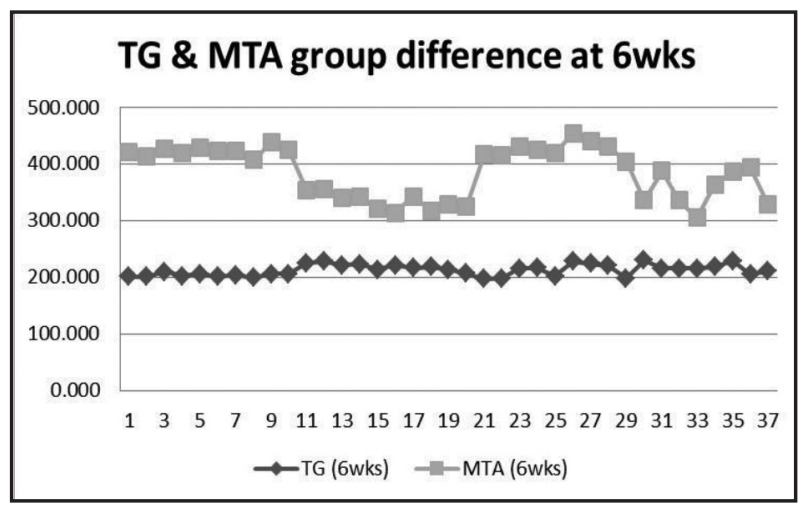

Figure (9) Linear graph chart illustrates the difference between both groups (TG \& MTA) at 6 weeks.

\section{DISCUSSION}

The hallmark of healing process of dental pulp is the reparative dentin that formed after direct pulp capping with any dental material. The cellularbased repair stimulation in various tissues is the target of any invented drug and it's proven that the $\mathrm{Wnt} / \beta$-catenin signalling pathway is responded immediately to any tissue injury and it seems to be crucial for its repair ${ }^{(35-36)}$. Glycogen synthase kinase 3 (GSK-3) is enzyme that plays a key role in the $\mathrm{Wnt} / \beta$-cat pathway signal transduction that in the Wnt ligand /receptor binding absence, phosphorylates Axin and $\beta$-catenin causing ubiquitination and degradation ${ }^{(37)}$. 
In this study, results clarified that the inhibition GSK3 by the specific inhibitors causes activation of the Wnt $/ \beta$-catenin signalling axis leading to expression of definitive specific genes. Moreover the biological efficacy of Tideglusib drug as inhibitor of GSK-3 in pulp tissue was evaluated using a rabbit model of pulp exposure.

The animal model selected in the present study was rabbits because of the bigger size of their teeth than other rodents' teeth, which make it more suitable for dental procedures ${ }^{(38)}$. Moreover, many teeth can be used in one rabbit reducing the number of animals used for any experiment ${ }^{(39)}$. As a positive control, MTA was chosen for this study since several studies revealed that MTA is better than conventional restorative materials in promoting the formation of reparative dentin ${ }^{(40,41)}$.

The current experiment, a period of 4 and 6 weeks was used to study the effect of capping materials on pulp tissues. We used the same time-interval used before to examine the effect of Tideglusib drug in other rodents ${ }^{(7)}$.

The cytotoxic effects of the Tideglusib drug on rabbit's pulp cells were investigated using the MTT assay. It is a reliable and sensitive colorimetric assay which measures cells viability ${ }^{(42)}$. In this study, treatment of rabbit's pulp cells with different doses of Tideglusib drug showed that the highest concentration of Tideglusib that was not cytotoxic to the dental pulp cells after $24 \mathrm{hr}$ in culture was $34 \mathrm{uM}$. These results were found to be different with the results of other study ${ }^{(7)}$, which reported that the safety dose is $50 \mathrm{uM}$; we suggested that this difference could be due to the different animal model as he used rats in his study whereas we used rabbits.

In current study we used the immunohistochemistry technique to detect the $\beta$-catenin antibody in the pulp tissue as the immune staining is important to functional description and may reveal additional information, where conventional histology is insufficient ${ }^{(43)}$.
The results of our study showed increase in the $\beta$-catenin expression rate after four weeks in both groups (TG \& MTA) with insignificant difference (P-value equal 0.415) between them; this supposed to be due to the activated Wnt/ $\beta$-Catenin pathway in both groups. The results are coinciding with other studies which pointed the activation of Wnt/ $\beta$-Catenin signalling pathway after damage and during the healing process ${ }^{(22,25,44)}$. Moreover, this finding was in according with another study, which found that odontoblast-like cells and dental pulp cells under the exposed area were $\beta$-catenin positive and during in vitro odontoblastic differentiation of dental pulp cells there was upregulation of $\beta$-catenin. These data suggested that $\beta$-catenin may participate in formation of reparative dentin and also might play an essential role in differentiation of odontoblasts ${ }^{(10,45)}$.

The immunohistochemical findings of the present study were consistent with another study which showed that the odontoblastic differentiation of stem cells derived from apical papilla may enhanced by activation of $\beta$-catenin ${ }^{(46)}$. In addition previous experiments suggested that $\beta$-catenin may interact with many transcriptional co-factors forming DNA binding complex which regulates target genes transcription ${ }^{(47,48)}$. This supports the null hypothesis of that increasing the expression of Axin2 is a result of increasing the $\beta$-catenin in nucleus which is done by GSK-3 inhibitor enzyme.

Data recorded from two groups (TG \& MTA) after 6 weeks revealed a decrease in the mean values of the MTA group with significant difference (P-value equal 0.000) when compared to TG group. The differences between the two groups might be displayed as a result of feedback inhibition of the Wnt/ $\beta$-catenin in MTA group. This feedback inhibition was due to the overexpression of Axin2 whereas in the Tideglusib group, the drug irreversibly inhibits the GSK-3 enzyme so the cycle is not inhibited yet. This suggestion was in agreement with previous research, which found that Axin2 is a down regulator of $\beta$-catenin level by the 
ability of the Axins to complex GSK3- $\beta$, $\beta$-catenin, and APC ${ }^{(49)}$. Regarding the Tideglusib drug, another study showed that Tideglusib drug can irreversibly inhibit GSK-3 which explains the uncontrolled level of $\beta$-catenin ${ }^{(50)}$.

In this study the polymerase chain reaction (PCR) technique was used to detect the expression of Axin2 gene in the pulp tissues of normal and treated teeth. This technique was used because it offered accurate and sensitive way to quantify the mRNA levels that is essential in biomedical researches ${ }^{(51)}$.

The results of present study showed that higher expression of Axin2 in the tooth treated with Tideglusib than negative control group (without treatment) by about 5 folds and about 1.5 fold in the tooth treated with MTA (positive control group). These finding might be explained by the activation of the $\mathrm{Wnt} / \beta$-Catenin signalling pathway by Tideglusib drug which caused entrancement of $\beta$-catenin to enter the nucleus and releasing this transcription genes (Axin2); this results was consistent with another previous study, which reported the high expression of Axin2 in relation with Tideglusib drug ${ }^{(7)}$.

It is still unclear if Axin2 has a direct promotive role in mediating $\beta$-catenin in process of odontoblastic differentiation although this study found that $\beta$-catenin regulates Axin 2 expression. Therefore, other studies should be carried out to eliminate the network of regulatory mechanism of $\beta$-catenin in odontoblastic differentiation of dental pulp cell during formation of reparative dentin.

\section{CONCLUSIONS}

From the previously mentioned results, the following could be concluded:

1. The Tideglusib drug causes activation of the Wnt/ B-Catenin signalling pathway and inhibits the degradation of $\beta$-catenin. B-catenin accumulates in the cytosol then translocates into the nucleus.
2. Small molecule GSK-3 agonists (Tideglusib drug) delivered via a biodegradable collagen sponge stimulates the expression of Axin2 transcription factor gene which is known to play a key role in regulation of odontoblast and osteoblast differentiation.

\section{REFERENCES}

1. Kawashima N, Okiji T. Odontoblasts: Specialized hardtissue-forming cells in the dentin-pulp complex. Congenit Anom (Kyoto).2016; 56: 144-53.

2. Rajan S, Ljunggren A, Manton D, Björkner A, McCullough M. Post-mitotic odontoblasts in health, disease, and regeneration. Arch Oral Biol. 2020; 109:104591.

3. Balic A. Biology explaining tooth repair and regeneration: a mini-review. Gerontology. 2018; 64: 382-8.

4. El-Sayed K, Elsalawy R, Ibrahim N, Gadalla M, Albargasy $\mathrm{H}$, Zahra N, et al. The Dental Pulp Stem/Progenitor CellsMediated Inflammatory-Regenerative Axis. Tissue Eng Part B Rev. 2019; 25:445-60.

5. Oz F, Bolay S, Bayazit E, Bicer C, Isikhan S. Long-term survival of different deep dentin caries treatments: A 5-year clinical study. Niger J Clin Pract. 2019; 22: 117-24

6. Morotomi T, Washio A, Kitamura C. Current and future options for dental pulp therapy. Jpn Dent Sci Rev. 2019; 55:5-11.

7. Neves V, Babb R, Chandrasekaran D, Sharpe P. Promotion of natural tooth repair by small molecule GSK3 antagonists. Sci Rep. 2017; 7:39654.

8. Volponi A, Zaugg, L, Neves V, Liu Y, Sharpe P. Tooth Repair and Regeneration. Curr Oral Health Rep. 2018; 5: 295-303.

9. Masuda Y, Sakagami H, Yokose S, Udagawa N. Effect of Small-molecule GSK3 Antagonist on Differentiation of Rat Dental Pulp Cells into Odontoblasts. In Vivo. 2020; 34:1071-5.

10. XiLu, Jun Yang, Shouliang Zhao, Shangfeng Liu.Advances of Wnt signalling pathway in dental development and potential clinical application. Organogenesis. 2019; 15: 101-10.

11. Steinhart Z, Angers S. Wnt signalling in development and tissue homeostasis. Development. 2018; 145: 146589.

12. Zaugg L, Banu A, Walther A, Chandrasekaran D, Babb $\mathrm{R}$, Salzlechner C, et al. Translation Approach for Dentine Regeneration Using GSK-3 Antagonists. J Dent Res. 2020; 99:544-51. 
13. Astudillo P. Extracellular matrix stiffness and $\mathrm{Wnt} / \beta$ catenin signalling in physiology and disease. Biochem Soc Trans. 2020; 48:1187-98.

14. Tu X, Delgado-Calle J, Condon K, Maycas M, Zhang H, Carlesso N, et al. Osteocytes mediate the anabolic actions of canonical Wnt/ $\beta$-catenin signaling in bone. Proc Natl Acad Sci U S A. 2015; 112:E478-86.

15. Wu X, Li Y, Wang F, Hu L, Li Y, Wang J, et al. Spatiotemporal Expression of Wnt/ $\beta$-catenin Signaling during Morphogenesis and Odontogenesis of Deciduous Molar in Miniature Pig. Int J Biol Sci. 2017; 13:1082-91.

16. Tatullo M, Makeeva I, Rengo S, Rengo C, Spagnuolo G, Codispoti B. Small molecule GSK-3 antagonists play a pivotal role in reducing the local inflammatory response, in promoting resident stem cell activation and in improving tissue repairing in regenerative dentistry. Histol Histopathol. 2019; 34:1195-203.

17. Yu T, Klein O. Molecular and cellular mechanisms of tooth development, homeostasis and repair. Development. 2020; 147:184754.

18. Ding C, Chen Z, Li J. From molecules to macrostructures: recent development of bioinspired hard tissue repair. Biomater Sci. 2017; 5:1435-49.

19. Wu M, Wang Y, Shao JZ, Wang J, Chen W, Li YP. Cbf $\beta$ governs osteoblast-adipocyte lineage commitment through enhancing $\beta$-catenin signaling and suppressing adipogenesis gene expression. Proc Natl Acad Sci U S A. 2017; 114:10119-24.

20. Duan P, Bonewald LF. The role of the Wnt/ $/$-catenin signaling pathway in formation and maintenance of bone and teeth. Int J Biochem Cell Biol. 2016; 77:23-9.

21. Tian L, Xiao H, Li M, Wu X, Xie Y, Zhou J, et al. A novel Sprouty4-ERK1/2-Wnt/ $\beta$-catenin regulatory loop in marrow stromal progenitor cells controls osteogenic and adipogenic differentiation. Metabolism. 2020; 105:154189.

22. Clevers H, Nusse R. Wnt/ $\beta$-Catenin Signaling, Disease, and Emerging Therapeutic Modalities. Cell. 2017; 169: 985-99.

23. Janda C, Dang L, You C, Chang J, Lau W, Zhong Z, et al. Surrogate Wnt agonists that phenocopy canonical Wnt and $\beta$-catenin signalling. Nature. 2017; 545:234-7.

24. Ota C, Baarsma H, Wagner D, Hilgendorff A, Königshoff M. Linking bronchopulmonary dysplasia to adult chronic lung diseases: role of WNT signaling. Mol Cell Pediatr. 2016; 3:34-47.
25. Babb R, Chandrasekaran D, Carvalho Moreno Neves V, Sharpe PT. Axin2-expressing cells differentiate into reparative odontoblasts via autocrine $\mathrm{Wnt} / \beta$-catenin signaling in response to tooth damage. Sci Rep. 2017; 7:3102.

26. Mancinelli R, Carpino G, Petrungaro S, Mammola C L, Tomaipitinca L, Filippini A, et al. Multifaceted Roles of GSK-3 in Cancer and Autophagy-Related Diseases. Oxid Med Cell Longev. 2017; 4629495.

27. Bahmad F, Chalhoub R, Harati H, Bou-Gharios J, Ballout F, Monzer A, et al. Specific Inhibition of GSK$3 \beta$ by Tideglusib: Potential Therapeutic Target for Neuroblastoma Cancer Stem Cells. bioRxiv. 2020.

28. Muneer A. Wnt and GSK3 Signaling Pathways in Bipolar Disorder: Clinical and Therapeutic Implications. Clin Psychopharmacol Neurosci.2017; 15: 100-14.

29. Duda P, Wiśniewski J, Wójtowicz T, WójcickaO, Jaśkiewicz M, Drulis-Fajdasz D, et al. Targeting GSK3 signaling as a potential therapy of neurodegenerative diseases and aging. Expert Opin Ther Targets. 2018; 22:833-48.

30. Lovestone S, Boada M, Dubois B, Hüll M, Rinne JO, Huppertz HJ, et al. A phase II trial of tideglusib in Alzheimer's disease. J Alzheimers Dis. 2015; 45: 75-88.

31. Fuchs C, Fustini N, Trazzi S, Gennaccaro L, Rimondini R, Ciani E. Treatment with the GSK3-beta inhibitor Tideglusib improves hippocampal development and memory performance in juvenile, but not adult, Cdk15 knockout mice. Eur J Neurosci. 2018; 47:1054-66.

32. Mossman, T. Rapid colorimetric assay for cellular growth and survival: application to proliferation and cytotoxicity assays. J Immunol Methods.1983; 65:55-63

33. Green MR, Sambrook J. Analysis and Normalization of Real-Time Polymerase Chain Reaction (PCR) Experimental Data. Cold Spring Harb Protoc. 2018.

34. Miller RT. Avoiding pitfalls in diagnostic immunohistochemistry-important technical aspects that every pathologist should know. Semin Diagn Pathol. 2019; 36:312-35.

35. Tamura M, Nemoto E. Role of the Wnt signaling molecules in the tooth. Jpn Dent Sci Rev. 2016; 52:75-83.

36. Ahmed G, Abouauf E, AbuBakr N, Dörfer C, El-Sayed K. Tissue Engineering Approaches for Enamel, Dentin, and Pulp Regeneration: An Update. Stem Cells Int.2020:5734539.

37. Noori M, Bhatt P, Courreges M, Ghazanfari D, Cuckler C, Orac $\mathrm{C}$, et al. Identification of a novel selective and potent inhibitor of glycogen synthase kinase-3. Am J Physiol Cell Physiol. 2019; 317: C1289-C1303. 
38. Salkın H, Gönen ZB, Özcan S, Bahar D, Lekesizcan A, Taheri S, et al. Effects of combination TGF-B1 transfection and platelet rich plasma (PRP) on three-dimension chondrogenic differentiation of rabbit dental pulp-derived mesenchymal stem cells. Connect Tissue Res. 2019; 1-12.

39. Mapara M, Thomas BS, Bhat KM. Rabbit as an animal model for experimental research. Dent Res J (Isfahan). 2012; 9:111-8.

40. Gamal A, Khattab N, Fouda T, Tohamy S. Histological Evaluation of Response to Direct Pulp Capping with Propolis: Experimental Study in Rabbit. International Journal of Advanced Research (IJAR). 2017; 5: 2325-33.

41. Tayyaba T, Rizwan J. Abd G, Naseer A, Zahid R, Sara J. The effect of mineral trioxide aggregate as a direct pulp capping agent in permanent teeth. J Int Oral Health. 2018; 10: $310-3$.

42. Profeta F, Matteucci O, Orsini G, Sonsini L, Lombardi G, Capista S, et al. Evaluation of veterinary autogenous vaccines safety by an MTT in-vitro cytotoxicity assay. Vet Ital. 2019; 55:299-305.

43. Sukswai N, Khoury JD. Immunohistochemistry Innovations for Diagnosis and Tissue-Based Biomarker Detection. Curr Hematol Malig Rep. 2019; 14:368-75.

44. Nishimura H, Nakamura O, Yamagami Y, Mori M, Horie R, Fukuoka N, et al. GSK-3 inhibitor inhibits cell proliferation and induces apoptosis in human osteosarcoma cells. Oncol. Rep. 2016; 35: 2348-54.
45. Yuan Z, Xue Y, Teresita B, Jill AH. A correlation between $\mathrm{Wnt} / \beta$-catenin signaling and the rate of dentin secretion. $\mathrm{J}$ Endod. 2019; 45:1357-64.

46. Wang J, Liu B, Gu S, Liang J. Effects of Wnt/beta-catenin signalling on proliferation and differentiation of apical papilla stem cells. Cell Prolif. 2012; 45: 121-31.

47. Ramakrishnan $\mathrm{AB}$, Cadigan KM. Wnt target genes and where to find them. F1000Res. 2017; 6:746.

48. Xu Z, Robitaille A, Berndt J, Davidson K, Fischer K, Mathieu J, et al. Wnt/ $\beta$-catenin promotes self-renewal of naïve hESCs. Proc Natl Acad Sci U S A. 2016; 113: E6382-90.

49. Bernkopf B, Brückner M, Hadjihannas V, Behrens J. An aggregon in conductin/axin2 regulates Wnt/ $\beta$-catenin signaling and holds potential for cancer therapy. Nat Commun. 2019; 10: 4251-66.

50. Domínguez JM, Fuertes A, Orozco L, Monte-Millán M, Delgado E, Medina M. Evidence for Irreversible Inhibition of Glycogen Synthase Kinase-3 by Tideglusib. J Biol Chemis. 2012; 287: 893-904.

51. Mesa L, Manrique R, Muskus C, Robledo S. Test accuracy of polymerase chain reaction methods against conventional diagnostic techniques for Cutaneous Leishmaniasis (CL) in patients with clinical or epidemiological suspicion of CL: Systematic review and meta-analysis. PLoS Negl Trop Dis. 2020; 14:e0007981. 